The time has come to talk of many things: some comments on Ogden and Friedman

Michael Murray

m.murray@keele.ac.uk

Keele University, UK

Uncorrected proof

Published in Health Psychology Review 2013 


\section{The time has come to talk of many things: some comments on Ogden and Friedman}

In our eagerness to develop new ideas there is often a reluctance to look back at how ideas have developed and how they are connected to culture and social circumstances. In his classic work on scientific paradigms Kuhn (1962) makes the point that much of what he called normal science is concerned with the dotting of ' $i$ 's and the crossing of ' $t$ 's. While this work is important it is often constrained by epistemological, methodological and disciplinary boundaries. To develop new insights there is a need to step back and to review the development of ideas, their underlying assumptions and their social and historical settings. As Gergen (1973) and others (e.g. Billig, 2008) have argued psychological ideas need to be studied historically. Our everyday practices and ways of thinking are socially, culturally and historically located. My aim when I wrote the previous article (Murray, 2013) was to begin this task of reviewing the setting within which health psychology developed and to begin to review the character of some of the key ideas in the field. The paper was in no way a comprehensive review of the field but rather a start. Hopefully, others will join me in this process of excavation which can only serve to strengthen psychology's contribution to promoting health and well-being.

Ogden (2013) and Friedman (2013) in their very interesting commentaries refer to the primary source of data that I used - textbooks. Both indicate that textbooks, especially those aimed at an undergraduate audience, often simplify issues and gloss over complexities. I would not argue with this assessment. I realise that textbooks only provide a limited sense of the complexity of the development of a field, in particular, a new field which is attempting to chart out its territory. It would seem that an important point in the early development of the field of health psychology was to stake a claim to having a distinctive contribution to understanding the complexities of health and illness. This was especially the case in the broader field of healthcare where biomedicine was and retains a dominating role in defining health and illness and methods of investigation. Fourteen years ago my colleague Kerry Chamberlain and I made this point:

"Medicine is an immensely powerful profession in the western world, where its standards and perspectives are broadly promoted and accepted as truth. Biomedicine is pervaded with the rhetoric of discoveries and cures. Working within the medical establishment, health psychologists have tended to follow the 'predict' and 'control' tenets of positivist science that are dominant there" (Murray \& Chamberlain, 1999: 5).

While this may be the case at the early stages of a new field the danger is that it becomes the only approach as claims to truth are promulgated in textbooks and integrated into training programmes. 
As we all know, I good education promotes challenge and debate rather than bland acceptance of ideas. Indeed, there are increasing numbers of examples of psychology textbooks which attempt to push the need for debate to the fore. This has been especially the case within social psychology with its links with critical social theory. A relatively early example was the text by Howett, Billig, Cramer, Edwards, Knoveton, Potter, \& Radley (1989) in which they attempted to deliberately promote discussion and debate rather than impart a single truth. More recent textbooks in social psychology have followed suit (e.g. Stainton Rogers, 2011; Dickerson, 2012). Within health psychology such debate is developing although it is less apparent in US textbooks where the natural science approach to research remains dominant.

Friedman makes the point that many of the early health psychologists were schooled in social psychology and so were aware of some of these debates. It is interesting to look back at some earlier commentaries on the field. In a summary paper on a collection of articles on the international development of health psychology over 20 years ago (Jansen \& Weinman, 1991) John Weinman makes a very germane point about the limitations of health psychology:

"it is clear that political, economic and social changes will have to occur in attempting to eliminate conditions such as poverty, unemployment and loneliness, all potent sources of ill health. Since many high risk individual behaviours (e.g. smoking; poor diet; high alcohol consumption) are often associated with these adverse social conditions, it will be quite inappropriate for health psychologists to pursue individual models $\mathrm{f}$ behaviour change as the only way of achieving 'health for all'. It will be necessary to adopt community-based approaches and to develop a better understanding of the social meanings of different risk behaviours and of the norms and value systems which underpin and maintain them. It will also be necessary to act to put pressure on such different groups and organisations as local politicians, food distributors, the media and environmental policy makers in order to provide a social climate in which it becomes easier for the individual to make health-related choices and to achieve health-related behaviour change (e.g. Elder, Abrams, Beaudin et al, 1988)" (Weinman, 1991: 160).

Unfortunately, this good advice was pushed to the sidelines in the enthusiasm to identify individual characteristics which could predict certain health practices. Indeed, this advice might even be described by Friedman as part of health psychology revolutionary past which has now been superseded by a more dispassionate scientific approach. It is unfortunate that debates about the nature of science seem to have been so neglected in health psychology, especially in North America. The ignorance of epistemological debate within much of health psychology can lead to the dismissal 
of certain approaches as being unscientific. Instead, we get discussion about more complex statistical analyses.

If we go back even further to the early origins of psychology as a science we can see concern about the dominance of natural science as the preferred method of investigation. For example, Wilhelm Wundt who is often held up as the father of experimental psychology developed an alternative 'volkerpsychologie' which promoted a social, cultural and historical approach to the study of human psychology. He also argued that all students of psychology should also study philosophy. It is interesting to note that although North America psychologists flocked to Leipzig to learn from Wundt they took back only his ideas on experimental psychology and ignored the rest. Wong (2009) in his critical review of the contribution of Wundt emphasises that although he promoted the use of natural science methods (experimentation and measurement) in psychology he did not consider psychology a natural science. The danger is that in developing health psychology we are also cutting of our more critical roots and in our rush for scientific respectability creating a field that is twodimensional and anodyne.

Similar rejection of early critical ideas is apparent in other health disciplines. For example, public health often pays lip service to Virchow's (1821-1902) argument:

"Medicine is a social science, and politics is nothing else but medicine on a large scale. Medicine, as a social science, as the science of human beings, has the obligation to point out problems and to attempt their theoretical solution: the politician, the practical anthropologist, must find the means for their actual solution... The physicians are the natural attorneys of the poor, and social problems fall to a large extent within their jurisdiction" (Mackenbach, 2009).

The scientising of public health also led to the loss of its original radical impulse which is now being reclaimed in the Spirit of 1848 caucus in the American Public Health Association (www.spiritof1848.org).

In my article I was encouraging health psychology to not wait so long but to urgently reflect upon its assumptions and values before it too becomes ossified. It should be emphasised that such historical inquiry is in no way designed as a reflected version of victim-blaming on individual researchers. As Ogden emphasises we are all children of certain times and carry with us certain assumptions about the nature of society and of science. Although we may differ in our approaches it is our common endeavour to promote health. The challenge remains to remain self-critical of our own approaches and receptive to new ideas which can sometimes be perceived as threatening (see Kaptein, 2012). 
Times change. The recent special issue of Health Psychology edited by Brendan Gough (2013) on men's health shows the growing acceptance of qualitative methods in the field. In other more European health psychology journals there has been an increasing acceptance of qualitative and critical approaches for some time (see Lyons, 2012).

Over 140 years ago Lewis Carroll's (1872) Tweedledee recited 'The Walrus and the Carpenter' to Alice which included a call by the walrus to be more expansive in our thinking:

"The time has come," the Walrus said,

"To talk of many things:

Of shoes--and ships--and sealing-wax--

Of cabbages--and kings--

And why the sea is boiling hot--

And whether pigs have wings."

Surely, the time has come for health psychology to ask new questions, explore new methods and develop new practices. Such questions should not be flights of fantasy or constrained by scientistic niceties but be grounded in the everyday lived experiences of ordinary people who suffer from too much poverty, disadvantage, despair, violence, cultural dislocation and associated ill-health. There is a lot more to a revitalised health psychology than more sophisticated statistical analyses no matter how important a role this can play. We need less normal science and greater reflection on the sociohistorical and cultural context of our research. Recently there has been growing debate about the imposition of western values and ideas within psychology (see Kim, Yang \& Hwang, 2006). There is an urgent need for health psychology to begin to consider the cultural locatedness of our work (see Maclachlan, 2006) and to explore the collaborative development of new methodologies and new practices (see Chilisa, 2012). 


\section{References}

Billig, M. (2008). The hidden roots of critical psychology. London: Sage.

Carroll, L. (1872/2011). Through the looking glass and what Alice found there. London: Macmillan.

Chilisa, B. (2012). Indigenous research methodologies. London: Sage.

Dickerson, P. (2012). Social psychology. Traditional and critical perspectives. Harlow: Pearson.

Friedman, H.S. (2013). Revolutionary health psychology versus scientific health psychology. Health Psychology Review, 5,

Gergen, K.J. (1973). Social psychology as history. Journal of Personality and Social Psychology, 26, 309-320.

Howett, D., Billig, M., Cramer, D., Edwards, D., Knoveton, B., Potter, J., \& Radley, A. (1989). Social Psychology: Conflicts and Continuities. Open University Press.

Kaptein, A. (2012). Pick up the pieces and go home - on the demise of health psychology. Health Psychology Review, 5, 39-47.

Kim, U., Yang, K.-S., \& Hwang, K.-K. (eds.) (2006). Indigenous and cultural psychology. Understanding people in context. New York: Spring.

Kuhn, T.S. (1962). The structure of scientific revolutions. Chicago: University of Chicago Press.

Jansen, M.A., \& Weinman, J. (Eds.) (1991). The international development of health psychology. Chur: Harwood Academic.

Lyons, A. C. (2012). Advancing and extending qualitative research in health psychology. Health Psychology, 5, 1-8.

Machenbach, J.P. (2009). Politics is nothing but medicine on a larger scale: reflections on public health's biggest idea. Journal of Epidemiology \& Community Health, 69, 181-184.

Maclachlan, M. (2004). Culture, empowerment and health. In M. Murray (ed.) Critical health psychology (pp. 101-118). London: Palgrave.

Murray, M., \& Chamberlain, K. (1999). Health psychology and qualitative research. In M. Murray \& K. Chamberlain (Eds.) Qualitative health psychology: Theories and methods (pp. 3-15). London: Sage. 
Ogden, J. (2013). The changing shape of Health Psychology: matter of progress or a sign of Thatcher's children coming of age? Health Psychology Review, 5,

Stainton Rogers, W. (2011). Social psychology. Second edition. Maidenhead: Open University Press.

Weinman, J. (1991). Determinants of health psychology's development. In M.A. Jansen \& J.

Weinman (Eds.) The international development of health psychology (pp. 165-171). Chur: Harwood Academic.

Wong, W. (2009). Retracing the footsteps of Wilhelm Wundt: Explorations in the disciplinary frontiers of psychology and in volkerpsychologie. History of Psychology, 12, 229-265. 